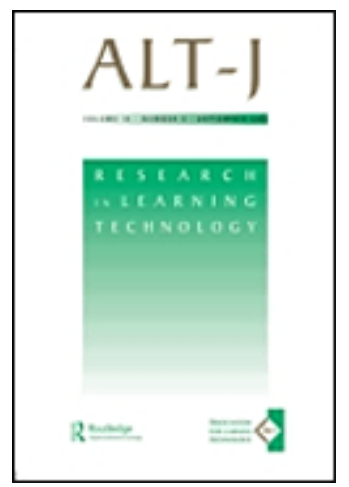

Beyond the Yellow Brick Road: Mobile web 2.0 informing a new institutional elearning strategy

\begin{tabular}{|r|l|}
\hline Journal: & ALT-J Research in Learning Technology \\
\hline Manuscript ID: & CALT-2010-0014.R1 \\
\hline Manuscript Type: & Case Study \\
\hline Keywords: & mlearning, web 2.0, case study \\
\hline \multicolumn{2}{l}{} \\
\hline
\end{tabular}

SCHOLARONE ${ }^{m}$ Manuscripts 


\title{
Beyond the Yellow Brick Road: Mobile web 2.0 informing a new institutional elearning strategy.
}

\begin{abstract}
Mobile Learning (mlearning) has moved beyond the realms of fantasy to become a viable platform for contextual learning that bridges formal and informal learning environments. This paper overviews how mobile web 2.0 has been instrumental in facilitating pedagogical change and informing an institutions new elearning strategy that focuses upon social constructivist pedagogies. The project developed an intentional Community Of Practice (COP) model for supporting new technology integration, pedagogical development, and institutional change. Beginning with a small selection of early adopter trials, the results of the research are now informing a wider integration of wireless mobile computing.
\end{abstract}

Keywords: mlearning; web 2.0; case study

\section{Introduction}

This paper reflects upon how the integration and support of mobile web 2.0 projects have transformed a tertiary education institution's approach to elearning. This transformational journey is based upon four years of research on appropriating the pedagogical benefits of web 2.0 and pedagogy 2.0 (McLoughlin and Lee 2008) anywhere anytime using mobile web 2.0 and wireless mobile devices (or WMDs), in particular WiFi (wireless ethernet) and 3G (third generation mobile 'broadband') enabled smartphones, and 3G enabled netbooks. A series of participatory action research (Swantz 2008; Wadsworth 1998) mlearning projects were used to draw out implications and strategies for facilitating social constructivist learning environments. These mlearning projects were situated within a variety of educational contexts, at different educational levels, and took place longitudinally across one to three years of implementation, involving cycles of reflection and refinement with earlier project results informing the design of the following projects. The learning contexts included: Bachelor of Product Design (2006 using Palm Lifedrive, 2008 using Nokia N80, N95, 2009 using Nokia XM5800, N95, N97), Diploma of 
Landscape Design (2006 Using Palm TX, 2007 using Nokia N80, 2008 using

Sonyericsson P1i, 2009 using Dell mini9 netbook), Diploma of Contemporary Music

(2008, 2009 using iPod Touch, iPhone 3G), Bachelor of Architecture (2009, using Nokia

XM5800 and Dell Mini9 netbook), and the Bachelor of Performing and Screen Arts

(2009 using Dell Mini9 netbook and Nokia XM5800). Overviews of these projects are

available online:

- http://prezi.com/kr94rajmvk9u/

- http://www.youtube.com/watch?v=FcwL8kQoRSI

- http://www.youtube.com/watch?v=5vGNWMwEypY

Aaaa is New Zealand's largest tertiary Technical Institute

(http://www.Aaaa.ac.nz). The institutions previous default model for lecturer professional development was delivery of an annual series of generic workshops, with very low attendance levels and invisible outcomes in students' educational experiences. The entrenched instructivist pedagogical teaching model has also been challenged and disrupted (Sharples 2001) by the implementation of mobile web 2.0, creating a shift to social constructivist teaching and learning paradigms. The resulting mobile web 2.0 support and implementation models developed from the research have been influential in informing the development of the institutions new elearning strategy, with many of the pedagogical and support strategies developed during these projects becoming integrated into this new elearning strategy. Thus the outcome of using an action research methodology has met the researcher's goal of having significant positive impact on the institution and the associated learning community.

The mlearning project research questions were: 
- What are the key factors in integrating Wireless Mobile Devices (WMDs) within tertiary education courses?

- What challenges/advantages to established pedagogies do these disruptive technologies present?

- To what extent can these WMDs be utilized to support learner interactivity, collaboration, communication, reflection and interest, and thus provide pedagogically rich learning environments that engage and motivate the learner?

- To what extent can WMDs be used to harness the potential of current and emerging social constructivist e-learning tools?

Data gathering consisted of:

- Pre-trial surveys of lecturers and students, to establish current practice and expertise

- Post-trial surveys and focus groups, to measure the impact of the wireless mobile computing environment, and the implementation of the guidelines.

- Lecturer and student reflections via their own blogs during the trial.

\section{Literature Review}

This section contextualises some of the core concepts underpinning the mlearning projects that then informed the institutions elearning strategy.

\section{Communities Of Practice}

An intentional communities of practice model (Langelier 2005) was developed by the researcher (Aaaaaaaa 2007; Aaaaaaaa and Kligyte 2007) and used to provide longitudinal lecturer professional development and technological support, and to provide pedagogical and technological scaffolding for the students throughout the length of the projects.

\section{Social Software and Communities of Practice}

Wenger (2005) discusses the contribution that technologies can make to communities of practice (COPs), in particular web 2.0, social software tools.

Social software (or web 2.0) tools make a natural companion to COPs. The key characteristics of social software fit well with social constructivist pedagogies, enabling a natural and relatively simple approach to creating collaborative learning communities (McLoughlin and Lee 2007; Mejias 2006). Web 2.0 is about moving beyond content 
delivery to an interactive collaborative environment with an emphasis upon sharing, ease of use, customization and personal publishing (Alexander 2006). Thus in an educational setting, web 2.0 provides opportunities for students to be involved in the learning process, to create their own unique collaborative environments that can be shared globally (JISC 2009b).

Wenger's exploration of the use of web 2.0 tools to enhance COPs (Wenger et al. 2009; Wenger et al. 2005) paralleled the early development of the researcher's research methodology. Wenger's largest influence on the research project was the development of the concept and role of the 'technology steward' within COPs.

\section{The Technology Steward}

Communities of Practice can be enhanced with the use of appropriate communications technologies when under the guidance of a Technology Steward. The Technology Steward (Wenger et al. 2005) is a member of the community with a grasp of how and what technologies can enhance the community. They act as a guide to the rest of the community as the community learns to utilize and benefit from technology. The technology steward thus forms a pivotal role in the successful integration of technology into the groups practice. As the research project has developed, and in particular with the development of an intentional COP model to support the pedagogical and technological integration of WMDs into each project, so has the understanding of the crucial role of the technology steward in supporting these projects. At the same time, Wenger also continued to develop his understanding of this key role within COPs in the twenty first century technological environment. 
Wenger et al (2009) see technology stewardship within COPs as an emergent role that is clearly distinguished from traditional information technology (IT) support.

The role of the technology steward was appropriated by the researcher within the context of COPs for lecturer professional development, followed by student communities of practice for scaffolding their learning during the mlearning projects. These were effectively 'intentional' communities of practice (Langelier 2005), focused on the pedagogical and technical support of the mlearning projects.

\section{Intentional Communities of Practice}

While classical COPs form organically and spontaneously, they can also be created intentionally and cultivated for specific purposes. Intentional communities of practice share the same characteristics as organic communities of practice, but have at their core a plan (Langelier 2005, p. 31). These are similar to semi-formal learning communities (Kukulska-Hulme and Pettit 2008) but more longitudinal throughout the length of the mlearning projects, and therefore creating collaborative projects between the 'technology steward', the course lecturers, and the students on the course.

\section{Mobile Web 2.0}

The author of this paper proposes that mlearning can support and enhance both the face to face and off campus teaching and learning contexts by using the wireless mobile devices as a means to leverage the potential of current and emerging collaborative and reflective e-learning tools (for example: blogs, wikis, RSS). These are often called social software or web 2.0 tools, facilitating student-generated content (Bruns 2008) and student-generated learning contexts (Cook et al. 2007). The WMD’s wireless connectivity and data gathering abilities (for example: photoblogging, video recording, 
voice recording, and text input) allow for bridging (Vavoula 2007a) the on and off campus learning contexts - facilitating "real world learning". In particular, the context bridging and media recording capabilities of today's smartphones make them ideal tools for mobile blogging. Smartphones allow a user to send text, photos, video and audio directly from the site of recording to the users online Blog. The integration of mobile web 2.0 within the courses has formed a catalyst for pedagogical change that the researcher as the technology steward within each community of practice has been able to explicitly capitalise upon.

\section{Case Studies}

The thirteen mlearning projects represented within the five case studies referred to herein provide rich examples of practical pedagogical integration of mlearning within a variety of tertiary education courses. In this section we briefly summarize the main lessons learnt from the three longest-running case studies.

The core activity of each of the projects is the creation and maintenance of a reflective Blog as part of a course group project, effectively creating student eportfolios. However the smartphone or netbook can be used to enhance almost any aspect of the course, as was illustrated by the range of activities used in the projects. Several unique affordances of the new generation of smartphones were focused on in the 2009 projects (Aaaaaaaa and Bateman 2010c). These affordances facilitate student created content and formative lecturer and peer feedback, core aspects of a social constructivist pedagogy that is foundational for the institutions new elearning strategy.

Case Study1: Diploma of Landscape Design 2007 to 2010 
The mobile web 2.0 project with the Diploma of Landscape Design was born out of a desire to provide flexibility and enable situated learning environments for students who are predominantly part-time, and to create authentic teams of students who work on realworld projects as part of their final year course. The course lecturer envisioned mobile web 2.0 tools as potential facilitators of this pedagogy, but required technological and pedagogical support to implement these ideas. In 2007 students used Nokia N80 smartphones to document and share their design for an exhibition garden at the annual Ellerslie Flowershow. The 2008 project integrated the use of smartphones for reporting a field-trip to Japan. The short-term nature of these projects and the wide-range of student experiences and capabilities in the increasingly mature and part-time student demographic of the course led to a rethink of the mobile web 2.00 integration in 2009 , and a focus upon $3 \mathrm{G}$ enabled netbooks for creating student eportfolios. Beginning in 2007, the first mlearning project (Aaaaaaaa 2009b) paved the way for the following projects, highlighting a range of technical and implementation issues that could be improved upon. The project also emphasized the disruptive nature of mlearning (Sharples 2001; Stead 2006), illustrating the process of lecturer pedagogical reconceptualisation of teaching, and the process of student reconceptualisation of learning required as the course moved from teacher-centred (pedagogy) to social constructivism (andragogy to heutagogy). Thus the importance of a robust yet flexible technical and pedagogical support strategy was highlighted. The unique student profile (all the students were aged between 43 and 69) of the 2008 iteration of the Landscape Design mlearning project highlighted the importance of choosing appropriate WMDs for the needs of each unique student group. Thus the 2009 Landscape Design mlearning 
project used netbooks to minimize the cognitive load for the students, and highlighted the importance of learning community formation to be integrated into the course (Aaaaaaaa et al. 2009a).

\title{
Lecturer Feedback
}

\begin{abstract}
We found that the 'e' and mlearning component of our project worked really well this year we've had extremely high participation from our students. They seem to really enjoy the ability to contribute to the discussions at any time digitally, and we had each group performing really well, the conversations between groups was good, and the multidisciplinary work with Design worked very well for us. So the group work was fantastic. The second aspect I wanted to mention was the learning environment that we setup with Thom's time. We set ourselves up in the back of Long Black Café in an open learning situation with the notebooks around a big table. It seemed to work very well. They liked the access to food, they enjoyed the aspect of all getting together once a week to blog and it seemed to spur them on to get going independently as well. (Lecturer, May 2009)
\end{abstract}

\section{Case Study2: Bachelor of Product Design 2008 to 2010}

Aspects of this case study have been published in various peer-reviewed papers

(Aaaaaaaa and Bateman 2009b; 2010a; b; Aaaaaaaa et al. 2009a; Aaaaaaaa et al. 2009b; c; Aaaaaaaa et al. 2009d). One of the key drivers for the introduction of mlearning into the course was the development of a flexible, context independent teaching and learning environment. The 2008 mlearning project was initially envisioned as a voluntary project involving two lecturers and eight students investigating the potential for bridging the on and off campus learning contexts using Nokia N95 smartphones. The enthusiastic response from the participants led to the implementation of mlearning projects across all three years of the course in semester two of 2008. These projects were followed up in 2009 with the full integration of mlearning with all of the students and lecturers in the three year classes of the course in a staged and scaffolded project with first year students using 3G netbooks and Nokia Xpressmusic 5800 smartphones, second year students 
using Xpressmusic 5800 smartphones and their own laptops, and third year students using Nokia N97 smartphones plus their own laptops.

The Product Design mlearning projects achieved significant progress in course integration, pedagogical reconceptualisation, and development of a staged and scaffolded implementation model for developing learning communities facilitated by intentional communities of practice across each year of the course. The case study illustrated the potential to stage and scaffold mlearning integration across all three years of a Bachelor level course, starting with establishing a learning community culture involving both the students and the lecturers and facilitation of a progression of teaching paradigms from pedagogy to heutagogy (PAH) (Luckin et al. 2008) following the first year to third year of the course. The PAH continuum maps well with the progression of mobile web 2.0 course integration from web 2.0 appropriation (JISC 2007; 2009a) in first year to student mobile facilitated content creation (Bruns 2007; JISC 2009b) in second year, and finally the context independence and bridging affordances of mlearning (Luckin et al. 2008; Vavoula 2007b) leveraged in the third year 'nomadic studio' (Aaaaaaaa et al. 2009a).

\title{
Lecturer Feedback
}

\begin{abstract}
The standard Atelier Method or studio teaching environment of one communal space and one timetable is unlikely to offer the best support and learning opportunities for today's creative students; it does not mirror the 'real contemporary world'. Over the last two to three years, the introduction of mobile web 2.0 tools into the Bachelor of Product Design has facilitated significant flexibility for students allowing them to stay connected, share their ideas widely, participate in world wide creative communities and choose to work in virtually any context on and off campus (Lecturer 2009).
\end{abstract}

\section{Case Study3: Diploma of Contemporary Music 2008 to 2010}

This project was centred on preparing students for the music technology paper that is part of the Diploma of Contemporary Music, which was scheduled to run for the first time in 
semester one of 2009. In this course students experiment with and evaluate current music creation and delivery technologies, including podcasting and sharing via blogs, eportfolios, and social networking. The goal of the project was to illustrate the potential of a PLE (Personal Learning Environment), facilitated by mobile web 2.0 technologies, that was unconstrained by the limitations of the institutional learning management system (LMS). For semester one of the project lecturers and students were provided with an iPod Touch (16GB) each, which was upgraded to a $3 \mathrm{G}$ iPhone in semester two when they become officially released in New Zealand.

It became clear that the iPhone project needed to be embedded in a course, with clearly related assessment tasks, for the students to participate more fully in it (Aaaaaaaa 2009a). In particular 2009 projects were designed to investigate the use of MySpace, student created podcasts, and microblogging as authentic mobile learning environments within the context of music delivery, promotion and critique.

The 2009 project was explicitly linked to two courses, one within the second year of the Diploma of Contemporary Music, the other within the first year of the course with second year students as peer mentors. Thus the integration of mlearning was staged across the two years of the course, and the use of mobile web 2.0 tools were integrated into the course assessment.

The Diploma of Contemporary Music mlearning project developed from an initial exploration of the potential of mlearning to engage students and enhance the course to an example of successful course integration and student adoption and appropriation of mlearning. During the first iteration of the mlearning project students and lecturers were enthusiastic and engaged by the tools, but skeptical as to the potential impact on the 
course and learning outcomes (Aaaaaaaa 2009a). The second iteration of the mlearning project integrated the mlearning tools into the course assessment leading to adoption and appropriation by the students beyond personal and social use, leveraging the learning context bridging (Vavoula 2007b) affordances of mobile web 2.0 for facilitating authentic (Herrington and Herrington 2007) course-related learning environments beyond the classroom. This case study also demonstrates the need for significant time for lecturer pedagogical reflection for the necessary ontological shifts (Chi and Hausmann 2003; Hameed and Shah 2009) in their pedagogical conceptions to be able to integrate mlearning authentically.

\section{Lecturer Feedback}

I think we're starting to see the students working in very different ways than what we've seen before. I think it's a very gradual process for them to adapt to this way of learning and what may help it is a lot more time and experience, but it's starting to work (Lecturer, 2009).

\section{Institutional Implications}

The impact of the integration of a community of practice model facilitated by a technology steward for pedagogical and technological support for the mlearning case studies is illustrated by the following lecturer feedback.

\footnotetext{
I can't say enough about your contribution to our Year 3 New Technologies mobile learning project this year. You facilitated it seamlessly, laying the initial groundwork by up-skilling the staff - all the while imbuing your training with the social-constructivist applications of the gear. This provided an initial context for these new communication tools, with which the Screen Arts staff involved shall always associate and use them. Next, you rolled-out the mobile tools to the students - well in advance of the actual classes (your suggestion) - and provided hands-on training (for the 19 students) in a very caring manner. At the end of their online presentations, you debriefed them in such a way as to allow them to look inside and assess the substantial value they derived from the project. Your attentiveness to the entire process demonstrates to me a thorough practitioner who cares very much about innovative facilitation and student outcomes (Lecturer, 2009).
} 
A limitation of the participatory action research methodology of the research is the significance of the input of the researcher as the technology steward for the projects. The partnerships developed between the researcher and the participants (particularly the lecturers) have been critical in supporting and providing direction for the projects. In order to create a transferable model to other learning contexts involving different technology stewards the role of eLearning Community Coordinator (eLCC) has been established within each department of the institution as a core part of the new elearning strategy.

\section{Introducing Unitec's eLearning Strategy (2010)}

Learning technologies or eLearning are critical components of a reconceptualised approach to teaching and learning at Unitec. The new strategy involves the utilisation of a range of learning technologies as integral parts of contemporary and engaging teaching and learning experiences. It is based on one powerful pedagogical idea - that the eLearning strategy will support Unitec's decision to reconceptualise all programmes within a commitment to a social constructivist pedagogy, or 'living curricula '. The strategy includes the following objectives:

1. To create authentic learning conversations that enable graduates to succeed in the 21 st century.

2. To provide accessible environments and creative solutions for students' access to online tools via Wireless Mobile Devices (WMDs).

3. To enhance wireless computing infrastructure.

The strategy focuses on three key areas: staff capability, student capability and access, and infrastructure changes. The community of practice model developed during the 
mlearning action research projects forms a core element of the new elearning strategy. Staff capability is enhanced by the establishment of eLearning Community Coordinators (eLCCs) within each department who facilitate departmental communities of practice. The eLCCs take on the role of technology stewards within these COPs as modelled within the mlearning projects. The eLCCs report to the institution's central professional development unit, of which the researcher is the elearning team leader. The establishment of the eLCCs role was launched in February 2010 with a week-long workshop facilitated by Etienne Wenger and Beverly Traynor (http://www.youtube.com/watch?v=U18BbjfK4Iw), modelling a COP approach to staff professional development, and authenticating the researcher's model.

As part of the elearning strategy, student access is facilitated by the specification of appropriate student-owned WMDs and the integrated use of these for class, tutorial and study sessions. Students with genuine hardships will be provided with institutionally owned WMDs for use in their courses.

The use of WMDs within each course is led by an evaluation of the potential pedagogical benefits to each course and how the utilisation of various learning technologies will be scaffolded across the length of the course. Investment in wireless infrastructure is being made to improve coverage, capacity and connection speed, and the sequential movement of staff computers from desktops to WMDs will be undertaken.

\section{Conclusions}

Participatory action research (McLoughlin and Lee 2007; Wadsworth 1998) has proven to be a useful methodology for this research, allowing the researcher to take on the key role of the 'technology steward' (Wenger et al. 2009; Wenger et al. 2005) to 
guide the projects as well as receive and act upon direct participant feedback, reflections, and critique, and subsequently modify the research process throughout the length of the research. The researcher has thus created an inter-related feedback loop between all of the mlearning projects across a variety of disciplines and contexts, channeling findings and reflections between each project. Significant beneficial change has been achieved for the various participants and stakeholders involved in the research, including demonstrable transformation in pedagogical strategies and pedagogical reconception from participating lecturers, increased engagement and collaboration from participating students, and strategic input into the institution's new elearning strategy (Aaaaaaaa and Bateman 2009a; 2010a; b; Aaaaaaaa et al. 2009a). While requiring time-intensive input from the researcher as the technology steward, the outcomes have been very rewarding, with the development of a sense of trust and collaboration between all the participants, and between the researcher and the course lecturers in particular. The researcher's role in facilitating these pedagogical changes is now being replicated throughout the institution with the development of the eLearning Community Coordinators within each department. The longitudinal exploration and implementation of a series of participatory action research mlearning projects has provided a model and momentum for transforming the professional development and student scaffolding models of the institution. The mlearning projects have also provided proof-of-concept that the pedagogical integration of WMDs into course curricula can provide a catalyst for pedagogical change towards a social constructivist pedagogy facilitating student-generated content and studentgenerated learning contexts beyond the classroom. The integration of the identified 
strategies and principles into the new elearning strategy provides an exciting opportunity

for the institution.

Thomas Aaaaaaaa (BE, BD, MTS, GDHE, MComp) is an Academic Advisor (eLearning and Learning Technologies) at Unitec New Zealand.

\section{References}

Alexander, B. 2006. Web 2.0: A new wave of innovation for teaching and learning? In Educause Review, 33-44.

Bruns, A. 2007. Beyond difference: Reconfiguring education for the user-led age. In ICE3: Ideas in cyberspace education: digital difference. Ross Priory, Loch Lomond.

Bruns, A. 2008. Blogs, wikipedia, second life, and beyond: From production to produsage Digital formations. New York: Peter Lang Publishing. http://www.amazon.com/Blogs-Wikipedia-Second-LifeBeyond/dp/0820488666/ref=sr_1_1?ie=UTF8\&s=books\&qid=1273792978\&sr=1 $\underline{-1}$

Chi, M. and R. Hausmann. 2003. Do radical discoveries require ontological shifts? In International handbook on innovation, eds Shavinina, L and Sternberg, R, 430 44. New York: Elsevier Science Ltd.

Aaaaaaaa, T. 2007. Moving mobile mainstream: Using communities of practice to develop educational technology literacy in tertiary academics. In MLearn 2007 Making the Connections 6th International Conference on Mobile Learning, ed. Oliver, C, 32-38. Melbourne Exhibition Centre, Melbourne.

Aaaaaaaa, T. 2009a. Contemporary music students and mobile technology. In Technology supported environment for personalised learning: Methods and case studies, ed. Odonoghue, J, 429 - 54. Hershey, PA 17033, USA: IGI Global.

Aaaaaaaa, T. 2009b. Mobilizing learning: Intentional disruption. Harnessing the potential of social software tools in higher education using wireless mobile devices. International Journal of Mobile Learning and Organisation 3, no. 4. Special edition: Developing Themes in Mobile Learning: 399 - 419.

Aaaaaaaa, T. and R. Bateman. 2009a. Transforming pedagogy using mobile web 2.0. International Journal of Mobile and Blended Learning 1, no. 4: 56-83.

Aaaaaaaa, T. and R. Bateman. 2009b. Transforming pedagogy using mobile web 2.0. Paper presentat at the IADIS International Conference on Mobile Learning 2009, 26 - 28 February, in Barcelona, Spain.

Aaaaaaa, T. and R. Bateman. 2010a. A mobile learning journey: Or "A tale of two academics pedagogical partnership". Paper presentat at the The 6th International Conference on Technology, Knowledge and Society 2010, 15-17 January, in Free University, Berlin, Germany.

Aaaaaaaa, T. and R. Bateman. 2010b. Reflections on 3 years of mlearning implementation (2007-2009). Paper presentat at the IADIS International Conference Mobile Learning 2010, 19 - 21 March, in Porto, Portugal. 
Aaaaaaaa, T. and R. Bateman. 2010c. Smartphones give you wings: Pedagogical affordances of mobile web 2.0. Australasian Journal of Educational Technology 26, no. 1: 1-14.

Aaaaaaa, T., R. Bateman, P. Cliffin, J. Gardner, I. Henderson and S. Holloway. 2009a. Mobilizing learning: Mobile web 2.0 scenarios in tertiary education. In EDULEARN09 the International Conference on Education and New Learning Technologies. Barcelona, Spain: International Association of Technology, Education and Development.

Aaaaaaaa, T., R. Bateman and I. Flitta. 2009b. Facilitating social constructivist learning environments for product design students using social software (web2) and wireless mobile devices. In Design/09 the Third International Conference on Design Principles and Practices, 15pp. Technical University Berlin, Germany.

Aaaaaaaa, T., R. Bateman and I. Flitta. 2009c. Integrating mobile web 2.0 within tertiary education. In m-ICTE2009, ed. Méndez-Vilas, A, 1348-52. Lisbon, Portugal: Formatex Research Center.

Aaaaaaaa, T., I. Flitta and R. Bateman. 2009d. Facilitating social constructivist learning environments for product design students using social software (web2) and wireless mobile devices. DESIGN Principles and Practices: An International Journal 3, no. 1: 15pp.

Aaaaaaaa, T. and G. Kligyte. 2007. Dummies2delight: Using communities of practice to develop educational technology literacy in tertiary academics. In JISC online conference: Innovating eLearning, 36-38. JISC online conference: JISC.

Cook, J., C. Bradley, J. Lance, C. Smith and R. Haynes. 2007. Generating learner contexts with mobile devices. In Mobile learning: Towards a research agenda, ed. Pachler, N, 55-73. London: WLE Centre, Institute of Education.

Hameed, K. and H. Shah. 2009. Mobile learning in higher education: Adoption and discussion criteria. In IADIS International Conference on Mobile Learning 2009, eds Sanchez, Ia and Isalias, P, 339 - 42. Barcelona, Spain: International Association for Development of the Information Society.

Herrington, A. and J. Herrington. 2007. Authentic mobile learning in higher education. In AARE 2007 International Educational Research Conference, ed. Jeffery, Pl. Fremantle, Australia: Papercode.

Jisc. 2007. In their own words: Exploring the learner's perspective on e-learning, 36. Bristol: Higher Education Funding Council for England.

Jisc. 2009a. Effective practice in a digital age. PDF.

Jisc. 2009b. Higher education in a web 2.0 world: JISC.

Kukulska-Hulme, A. and J. Pettit. 2008. Semi-formal learning communities for professional development in mobile learning. Journal of Computing in Higher Education 20, no. 2: 35-47.

Langelier, L. 2005. Working, learning and collaborating in a network: Guide to the implementation and leadership of intentional communities of practice, 170. Quebec City: CEFIRO (Recherche et Études de cas collection).

Luckin, R., W. Clark, F. Garnett, A. Whitworth, J. Akass, J. Cook, P. Day, N. Ecclesfield, T. Hamilton and J. Robertson. 2008. Learner generated contexts: A framework to support the effective use of technology to support learning, ed. Luckin, R. London: The London Knowledge Lab. 
Mcloughlin, C. and M. Lee. 2007. Social software and participatory learning: Pedagogical choices with technology affordances in the web 2.0 era. In Ascilite 2007, ICT: Providing Choices for Learners and Learning, eds Atkinson, Rj, Mcbeath, C, Soong, Ska and Cheers, C, 664-75. Centre for Educational Development, Nanyang Technological University, Singapore.

Mcloughlin, C. and M. Lee. 2008. Future learning landscapes: Transforming pedagogy through social software. Innovate: Journal of Online Education 4, no. 5: 7.

Mejias, U. 2006. Teaching social software with social software. Innovate 2, no. 5.

Sharples, M. 2001. Disruptive devices: Mobile technology for conversational learning. International Journal of Continuing Education and Lifelong Learning 12, no. 5/6: 504-20.

Stead, G. 2006. Mobile technologies: Transforming the future of learning. In Emerging technologies for learning, ed. Pinder, A, 6-15. Coventry: British Educational Communications and Technology Agency.

Swantz, M.L. 2008. Participatory action research as practice. In The sage handbook of action research: Participative inquiry and practice, eds Reason, $\mathrm{P}$ and Bradbury, H, 31- 48. London: SAGE Publications.

Vavoula, G. 2007a. Learning bridges: A role for mobile technologies in education. Educational Technology Magazine 47, no. 3: 33-37.

Vavoula, G. 2007b. Learning bridges: A role for mobile technologies in education. Paper presentat at the M-Learning Symposium, 9 February, in WLE Centre, Institute of Education, University of London.

Wadsworth, Y. 1998. What is participatory action research? Action Research International 2002 (no. May 3), http://www.scu.edu.au/schools/gcm/ar/ari/pywadsworth98.html (accessed.

Wenger, E., N. White and J. Smith. 2009. Digital habitats: Stewarding technology for communities. Portland, Oregon: CPsquare. http://technologyforcommunities.com/

Wenger, E., N. White, J. Smith and K. Rowe. 2005. Technology for communities. In Working, learning and collaborating in a network: Guide to the implementation and leadership of intentional communities of practice, ed. Langelier, L, 71-94. Quebec City: CEFIRO. 